\title{
DESENVOLVIMENTO DAS CRIANÇAS: UM OLHAR SOBRE O PAPEL DA FAMÍLIA E O PAPEL DA ESCOLA NA PERSPECTIVA DOS PAIS
}

DEVELOPMENT OF CHILDREN: THE CONCEPTION OF THE FAMILY'S ROLE AND SCHOOL'S ROLE IN VIEW OF THE FAMILY

DESARROLLO DE LOS NIÑOS: LA CONCEPCIÓN SOBRE EL PAPEL DE LA FAMILIA Y EL PAPEL DE LA ESCUELA EN VISTA DE LOS PADRES

\author{
Sabrina Magossi Mainardi* \\ Mary Yoko Okamoto
}

\begin{abstract}
RESUMO
Este trabalho refere-se a uma pesquisa qualitativa cujos objetivos consistiram em identificar as concepções e a compreensão da família a respeito da importância e do papel da escola e da família para o desenvolvimento das crianças. Para a coleta de dados foram realizadas entrevistas semidirigidas com pais de alunos do primeiro ano do Ensino Fundamental, de escolas municipais cuja permanência da criança é em tempo integral, no município de Assis/SP, nas quais foi possível perceber um descompasso entre a função familiar e a escolar. Devido às transformações sociais e familiares dos últimos séculos, nota-se que a família sofreu um enfraquecimento no desempenho de seu papel, depositando parte da responsabilidade sobre o desenvolvimento cognitivo e emocional de seus filhos na escola. Esta também se transformou, incorporou novas funções, como é possível observar na ampliação da jornada escolar que a mesma passou.
\end{abstract}

Palavras-chave: Família. Escola. Relação família - escola.

\begin{abstract}
This work refers to a qualitative research, whose objectives were to identify the concepts and the understanding of the family about the importance and role of school and family for the development of children. For the data collection semi-structured interviews were conducted with parents of students of the first year of Elementary School, municipal schools whose permanency of the children is full time, in the city of Assisi/SP, in which
\end{abstract}

\footnotetext{
Texto recebido em 06 de agosto de 2014 e aprovado para publicação em 19 de março de 2015.

* Graduanda do curso de Psicologia da Faculdade de Ciências e Letras de Assis - FCL - Universidade Estadual Paulista "Júlio de Mesquita Filho".E-mail: sabrina_mainardi@hotmail.com

** Possui graduação em Psicologia pela Universidade Estadual Paulista Júlio de Mesquita Filho (1992), mestrado em Psicologia pela Universidade Estadual Paulista Júlio de Mesquita Filho (2001) e doutorado em Psicologia (Psicologia Clínica) pela Pontifícia Universidade Católica de São Paulo (2007). Atualmente é professor assistente doutor da Universidade Estadual Paulista Júlio de Mesquita Filho - UNESP - Faculdade de Ciências e Letras de Assis.E-mail: mary.ok@uol.com.br
} 
it was possible to realize a dissonance between the function family and the school. Due to social changes and family of the last centuries, it should be noted that the family has suffered a decline in the performance of its role, depositing part of the responsibility on the cognitive and emotional development of their children in school. This also became, incorporated new functions, as can be seen in extension of school day that the same passed.

Keywords: Family. School. Relationship family-school.

\section{RESUMEN}

Este trabajo se refiere a una pesquisa cualitativa cuyos objetivos consistirán en identificar las concepciones y la comprensión de la familia sobre la importancia y el papel de la escuela y la familia relacionados al desarrollo de los niños. Para recopilación de datos fueron realizadas encuestas semiestructuradas con padres de alumnos del primer año, que están em la escuela en tiempo completo, de la Enseñanza Fundamentalde escuelas municipales, en el municipio de Assis/SP, en las cuales fue posible percibir un descompás entre la función familiar y la escolar. Debido a los cambios sociales y familiares de los últimos siglos, se nota que la familia sufrió un enflaquecimiento en el desempeño de su papel, poniendo algo de responsabilidad sobre el desarrollo cognitivo y emocional de sus hijos en la escuela. Ésta también se transformó, incorporó nuevas funciones, como se puede ver en la ampliación de la jornada escolar que pasó.

Palabras clave: Familia. Escuela. Relación familia-escuela.

\section{INTRODUÇÃO}

\subsection{As transformações na família e suas características educativas na atualidade}

A partir do século XVII, mudanças sociais, políticas e econômicas incidiram sobre a vida familiar e esta deixou de ser pública, comunitária e com pouca intimidade para viver outra realidade, na qual se fechou e passou a crescer à medida que a sociedade se retraiu. Dessa forma, a família moderna se responsabilizou pela construção do caráter, personalidade e desenvolvimento, tanto biológico quanto da cognição dos seres humanos. Essa família tornou-se a estrutura social básica, na qual diferentes pessoas convivem entre si e possuem uma relação com a sociedade (Ariès, 1981).

Deste modo, é na família que ocorrem os primeiros encontros com os "outros", através dos quais ocorre o aprendizado do modo humano de existir. Por meio do 
contato da criança com esses outros, essa se constrói como sujeito integrante de um mundo social com significados.

Considerando a visão e o conceito de desenvolvimento infantil e da função da família do ponto de vista psicanalítico, tem-se a concepção de que a família desempenha uma função essencial para o desenvolvimento de seus filhos, o de contenção da parte imatura da personalidade: os narcisismos, as pulsões incestuosas, o auto-erotismo, a hostilidade e a tendência à simbiose, possibilitando assim, o desenvolvimento do humano, limitando a situação narcísica e modificando-se em um adulto formado.

Segundo Dolto (1999), a família age de acordo com a educação que os progenitores receberam e tal educação não ocorre apenas através do discurso, constituindo-se em um:

"modo de ser que inspira à criança confiança em si ou desconfiança de si própria, que inculca o orgulho do seu sexo e de suas iniciativas, que lhe dá a segurança de que, faça o que fizer, é sempre amada, mesmo que seja às vezes repreendida". (Dolto, 1999, p.41)

Tal fato aponta para a importância do papel parental no desenvolvimento físico e emocional das crianças. Enquanto ensinam, os pais também exercem a função de autoridade, de fundamental importância para a contenção dos impulsos destrutivos da criança e de sua inserção na vida social. Essa autoridade seria uma forma de oferecer limites e a noção de realidade, que contribuiria para a capacidade de aprendizagem e contato com o conhecimento (Rojas, 2010; Roudinesco, 2003).

O século XX trouxe muitas mudanças na maneira de se pensar a infância e as práticas de cuidado e a educação dos filhos. Segundo Gomes e Zanetti (2011), o fenômeno da fragilização das funções parentais pode ser entendido como característico de pais que sentem culpa, dúvida e insegurança ao seu posicionamento, enquanto pais, diante de seus filhos e isto é esperado numa sociedade em constante transformação.

É importante dizer que por maiores que sejam as modificações na configuração familiar e na sociedade, essa instituição - a família - permanece como modelo de identificação, que distribuem normas e ideais; são os primeiros objetos de amor e ódio, transmissores de uma cultura (Janin, 2011), cooperando assim, para o desenvolvimento de seus componentes, seja este saudável ou patológico.

A família, por sua vez, também desempenha seu papel primordial no processo de escolarização dos filhos. Esses dois sistemas - escola e família - "têm objetivos 
distintos, mas que se interpenetram" (Oliveira \& Marinho-Araújo, 2010). As famílias, as escolas e as comunidades podem compartilhar a responsabilidade pelo bom desempenho acadêmico dos alunos, permanecendo cada um com seus devidos papeis.

Porém, é necessário que se possa pensar a respeito dos resultados produzidos por esse cenário de transformações no qual a família está inserida ao longo dos últimos séculos, as quais afetaram as configuraçōes familiares e seu funcionamento, ou seja, a organização e o desempenho de sua função.

Um dos aspectos observáveis diz respeito ao descentramento da família, no que se refere à constituição psíquica de seus filhos. Com a entrada cada vez mais precoce das crianças em instituições escolares e a necessidade de que grande parte de sua educação esteja vinculada a tais instituições, Rojas (2010) produz uma reflexão a respeito do desenvolvimento da função de apoio e sustentação do psiquismo, uma das tarefas primordiais exercidas pela família.

A constituição psíquica da criança depende em grande parte do apoio psíquico exercido pelas figuras parentais, os quais servem de sustentação para os impulsos da criança. Porém, para que tal função possa ocorrer, é necessária a existência da assimetria adulto-criança, que se refere à diferenciação inicial existente entre tais sujeitos, a qual confere uma formação subjetiva e ao mesmo tempo, uma responsabilidade singular dos adultos, que facilitariam a diferenciação da criança como um sujeito.

Diante desse cenário de mudanças que afetou o funcionamento familiar, segundo Rojas (2010), é muito comum a existência de uma situação de simetria ou mesmo de inversão nessa posição adulto-criança, cujos resultados são o déficit dos laços protetores e o desamparo das crianças, uma vez que se investe responsabilidade, poder e exigências excessivamente às mesmas, gerando o sentimento de desproteção e temor; afinal, nessa condição, os filhos não têm em quem se apoiar para que possam se desenvolver.

Além disso, outra consequência percebida diz respeito ao projeto de idealização que permeia o imaginário dos pais em relação aos filhos, nos quais existe uma grande expectativa de realização e perfeição depositada nos descendentes.

Enquanto ocupam a posição fantasmática de "sua majestade o bebê", pelo massivo investimento libidinal realizado pelas figuras parentais, os filhos iriam idealmente realizar tudo aquilo que estes não puderam empreender na existência, justamente porque se sacrificaram pelos filhos no campo biopolítico da família moderna. Com efeito, enquanto condensação maior do Capital econômico e simbólico da nação, a criança foi alçada à condição de soberana, pois a qualidade de vida da população, como signo maior que seria da riqueza do Estado, dependeria deste lugar onipotente conferido ao infante. Foi 
apenas neste contexto histórico, marcado que foi pela biopolítica, enfim, que a criança foi transformada no símbolo do futuro propriamente dito, que passou a colorir e encantar os nossos fantasmas sobre o infantil e a criança. (Birman, 2007, p.54)

Por último, cabe apontar a preocupação cada vez maior com a normatividade do comportamento expressa, sobretudo, na tendência a defini-lo através de um conjunto de sinais e sintomas, impulsionados principalmente pelo desenvolvimento tecnológico e de pesquisas em neurociências, cujo principal resultado pode ser apontado no espaço ocupado pelo discurso do "especialista" em detrimento do saber transmitido e conhecido pela família de modo geracional. Paulatinamente, o saber familiar tem sido substituído pelo discurso técnico-científico. Com isso, "não resta â família a não ser situar-se à margem das dificuldades da criança, indicando uma desresponsabilização e impotência que passam a marcá-la" (Mariotto \& Schaedler, 2013).

Tal cenário apresentado confere uma singularidade ao contexto familiar atual e consequentemente, à educação das crianças, seja no âmbito familiar como no escolar.

\subsection{A importância e o papel da instituição escolar na atualidade}

De acordo com Giddens (2002), na modernidade, o Estado e a sociedade civil se reordenaram e produziram transformaçôes. Assim, o Estado passou a influir cada vez mais na vida diária da população em geral, através das diversas instituiçôes e políticas públicas que atingem diversos aspectos da vida. Nesse sentido, existe a dicotomia entre sociedade civil - estruturada como o lado oposto da penetração do Estado na vida diária, e o domínio do público, ou seja, o Estado.

O surgimento da privacidade foi certamente dependente de uma separação adicional, a da infância em relação à vida adulta. Com essa nova denominação - infância - passou-se a olhar para essa fase com mais cuidado e atenção. De acordo com Ariès (1981), esse processo deu origem ao "sentimento moderno da família” no qual, dentre outras características, encontra-se a preocupação em proporcionar a todos os filhos, indistintamente, uma preparação para a vida associada à intensa preocupação e importância da educação dos filhos. A "aprendizagem tradicional foi substituída pela escola, uma escola transformada, instrumento de disciplina severa, protegida pela justiça e pela política." (Ariès, 1981, p. 277) 
"A educação é num certo sentido uma atividade pública, pois funciona fora de casa. Mas permanece para os alunos um ambiente segregado distinto do mundo adulto do trabalho e de outros envolvimentos" (Giddens, 2002, p.142). Dessa maneira, o público passou a penetrar em vários aspectos da vida privada, como por exemplo, a do ensino de boas maneiras e atividades básicas do cotidiano nas escolas, que anteriormente eram função da família. A família, por sua vez, passa a depositar cada vez mais confiança na instituição escolar, pois estas permanecem por maiores períodos de tempo na escola.

No Brasil, em meados da década de 30, a escola pública passou a ocupar um lugar enquanto uma instituição estratégica para o bem-estar da criança (Freitas, 2009). Esta instituição já teve como propósito retirar as crianças do mundo da rua, dando-lhes alimentação, segurança e ocupação do tempo com atividades pré-planejadas. "A escola apresenta-se como antítese do mundo privado [... ], ao mesmo tempo que oferece uma ponte entre a casa e os aposentos escolares com o fim de 'passar por cima' da rua." (Freitas, 2009, p. 81).

Tal fato demonstra, mais uma vez, a confiança depositada pelos pais nas instituições escolares, cuja função histórica está relacionada a retirar as crianças dos perigos da rua. Essa grande confiança depositada gradativa e progressivamente pela família na escola teve como uma das consequências uma crise na relação entre as instituiçóes, que ao que tudo indica, ainda levará algum tempo para ser resolvida. Assim, diante das dificuldades de exercício das funções parentais na educação da sua prole e no acompanhamento escolar de seus filhos, os pais passaram a exigir que a instituição escolar realize não apenas seu papel inicial, do ensino, como foi instituído com a escola no século XIX, e sim papeis que anteriormente constituíam-se como da família.

As escolas relutam em fazer isso, pois modificaria inteiramente a sua estrutura, e a questão permanece em aberto. As creches e as escolas maternais entraram já em parte na transmissão da socialização primária, que outrora era atribuição exclusiva da família, na ausência relativa dos pais nos primeiros anos de vida da criança. Parece-me, no entanto, que um novo pacto social entre a família e a escola será instituído no futuro, considerando as transformações que estão em curso (Birman, 2007, p. 58).

Esse processo de valorização da escola pode sintetizar todo o processo social que ocorre paralelamente ao enfraquecimento da família, impulsionada à vinculação do sofrimento psíquico a processos orgânicos, na qual a escola surge como "o espaço privilegiado de articulação entre o saber técnico dos médicos e a 'ortopedia química' a ser realizada nas crianças, de modo a ajustá-la a um ideal de normalidade engendrado na pós-modernidade, representado pelo sujeito bemadaptado, produtivo e feliz" (Mariotto \& Schaedler, 2013). 


\subsection{Uma nova configuração da escola: a ampliação da jornada escolar}

A educação escolar vem sofrendo mudanças e modificações em seu currículo, tempo e espaço desde os seus primórdios, e tal aspecto é perceptível na ampliação da jornada escolar que vem ocorrendo em diversos países, inclusive no Brasil. As transformaçôes na educação escolar acontecem juntamente com as mudanças na sociedade e nos meios produtivos, como também, esta sofre variaçôes de acordo com a demanda da população (Rocha, 2005).

No estado de São Paulo, essa ampliação da carga horária escolar se materializa através do projeto Escola de Tempo Integral que foi instituído durante a gestão do governo estadual, no período compreendido entre 2003-2006.

$\mathrm{Na}$ proposta inicial, o objetivo principal consistia em prolongar o tempo diário de permanência dos alunos de 5 para 9 horas diárias, com a finalidade de ampliar as possibilidades de aprendizagem, através de propostas de oficinas curriculares compostas por: Orientação para estudo e Pesquisa, Atividades de Linguagem e de Matemática, Atividades Artísticas, Esportivas/Motoras e de Participação Social (São Paulo, 2005 apud Castro \& Lopes, 2011). As oficinas curriculares desenvolverão, por sua vez, atividades práticas, inovadoras, integradas às temáticas e conhecimentos já interiorizados ou não pelos alunos (São Paulo, 2006, p. 14 apud Castro \& Lopes, 2011).

A proposta da Escola de Tempo Integral visa enriquecer o currículo dos alunos com conteúdos formais e informais da educação. Com isso, nessa proposta, a escola oferece

oportunidades variadas para que os alunos desenvolvam sua percepção do mundo, sua sensibilidade, sua autoconfiança e competência comunicativa por meio de atividades lúdicas, culturais, esportivas, artísticas e de comunicação que refletirão significativamente em seu desempenho escolar. (Vetorazzi, 2011, p. 25).

É possível notar nessa proposta, os objetivos da ampliação da jornada escolar e os propósitos das modificaçóes sofridas pela escola, desde sua proposta e currículo, até o tempo de permanência dos alunos nas mesmas, aliando, desse modo, o enriquecimento acadêmico e cultural dos alunos nela matriculados.

\section{MÉTODO}

Esse artigo é resultado de uma pesquisa que teve como objetivo geral identificar as concepções e a compreensão da família a respeito da importância e função desempenhadas pela escola e pela própria família para o desenvolvimento de 
seus filhos, em crianças matriculadas em escolas de regime integral. Para atingir tais objetivos, foram entrevistados pais de alunos matriculados no primeiro ano do ensino fundamental e que frequentam a escola em período integral, no município de Assis/SP.

A pesquisa qualitativa foi utilizada nessa pesquisa, uma vez que permite investigações que acessem concepções, significados, aspirações, crenças e atitudes as quais se mostram difíceis de serem quantificadas. Além disso, nessa modalide de pesquisa, pode-se ter acesso às vivências individuais ou coletivas estudadas, para compreender os significados atribuídos pois a principal fonte de dados tem oriem na acepção que os sujeitos têm sobre o meio que os circunda (Denzin \& Lincoln, 2005).

Inicialmente foi enviado um requerimento para a Secretaria da Educação do município de Assis/SP, solicitando a autorização para o desenvolvimento de nossa pesquisa e para a entrada em campo em escolas municipais que atendem em regime de tempo integral.

Após a aceitação de tal pedido, foram escolhidas duas escolas. Apesar da existência de seis escolas no município que atendem a tal critério, em uma delas, a permanência dos alunos em tempo integral é opcional. Além disso, em outras duas escolas, a implantação dessa modalidade de ensino é recente, por isso, encontram-se em um período de adaptação. Dessa maneira, como critério para a escolha de tais instituições, foi utilizado o tempo de funcionamento e a consolidação da implantação do regime de permanência em tempo integral.

Após a escolha das escolas, foi estabelecido um contato inicial com a direção de ambas para a apresentação dos objetivos da pesquisa e foi solicitada às mesmas a indicação de pais de alunos, em cada escola, que possuíssem filhos que frequentavam o $1^{\circ}$ ano do Ensino Fundamental em período integral pela primeira vez, para a realização de entrevistas.

Foram realizadas seis entrevistas semi-dirigidas, e o estabelecimento de tal número ocorreu devido à saturação dos dados para os objetivos da pesquisa, uma vez que essa pesquisa tem uma proposta qualitativa.

Apesar do convite de participação ter sido feito a pais de crianças, compareceram apenas as mães e uma avó; portanto, não houve a participação de nenhum pai. No total, foram realizadas 6 entrevistas semidirigidas com 5 mães e 1 avó.

Os temas investigados referiam-se à compreensão dos pais sobre permanência do filho numa escola em regime de tempo integral, sua importância e papel para o desenvolvimento de seus filhos; o papel e sua importância como pais e da família para o desenvolvimento dos filhos. 
As entrevistadas que compuseram a amostra foram: $\mathrm{Maria}^{1}, \mathrm{Lucia}^{2}, \mathrm{Carmem}^{3}$, Silvia ${ }^{4}$, Cristina ${ }^{5}$ e Fátima ${ }^{6}$. Todos os nomes utilizados são fictícios para preservar a identidade das entrevistadas e as entrevistas foram gravadas após a explicitação dos objetivos, garantia de sigilo e da assinatura do Termo de Consentimento Livre e Esclarecido ${ }^{7}$.

Após o término da coleta de dados, houve a preparação inicial do material, que consistiu na transcrição das entrevistas gravadas em áudio, em seguida, a leitura do material coletado e finalmente, a organização em eixos temáticos de acordo com as narrativas dos entrevistados $\mathrm{A}$ análise das entrevistas foi realizada por meio da análise do discurso, numa abordagem qualitativa. Através da análise de discurso é possível interrogar os sentidos que os sujeitos atribuem a suas narrativas e a partir disso realizar uma interpretação de tais sentidos. Assim, não se buscou uma verdade universal e generalizante, uma vez que foi levada em consideração a premissa de que as formas discursivas dos sujeitos entrevistados são singulares e cada uma delas se estabelece de maneira diferente na relação entrevistado e entrevistador. Nessa abordagem, considera-se que a linguagem é constituída na vida social e está presente no imaginário social. Ou seja, relaciona-se ao sistema de ideias ao qual esta representação está ligada, portanto, a interpretação do discurso ocorre no nível simbólico em busca da significação (Peräkylä, 2005).

Os dados foram interpretados através da teoria psicanalítica sobre o desenvolvimento infantil e da família e com as contribuições da sociologia para a compreensão da instituição familiar e escolar. Após as conclusões finais, o pesquisador realizou uma devolutiva dos resultados obtidos aos participantes da pesquisa.

\section{RESULTADOS E DISCUSSÃO}

Nesse momento, serão apresentadas as categorias analisadas na referida pesquisa, de acordo com os discursos das entrevistas realizadas com as mães.

140 anos, casada, do lar, com 4 filhos e ensino fundamental completo. Entrevistada em uma sala de aula na própria escola de sua filha. Datada entrevista: 03/06/2013

223 anos, solteira, autônoma, 2 filhos e ensino fundamental incompleto. Entrevistada em uma sala de aula na própria escola de seu filho. Datada entrevista: 05/06/2013

334 anos, solteira, vendedora, 2 filhos e ensino fundamental incompleto. Entrevistada em uma sala de aula na própria escola de seu filho. Datada entrevista: 05/06/2013

431 anos, casada, vendedora, 3 filhos e ensino médio incompleto. Entrevistada em uma sala de aula na própria escola de sua filha. Datada entrevista: 06/06/2013

531 anos, casada, do lar, 3 filhos e ensino fundamental completo. Entrevistada em uma sala de aula na própria escola de seu filho. Datada entrevista: 15/05/2013

651 anos, 2 filhos, divorciada, manicure e ensino fundamental incompleto, avó de uma criança. Entrevistada em uma sala de aula na própria escola de sua neta. Datada entrevista: 15/05/2013

7 A pesquisa foi aprovada pelo Comitê de Ética em Pesquisa da Faculdade de Ciências e Letras de Assis, (Protocolo 02617212.6.0000.5401). 


\subsection{A importância de uma escola que atenda os filhos em tempo integral}

Para as mães, a importância atribuída a uma escola que atenda em período de tempo integral refere-se principalmente ao desenvolvimento de habilidades cognitivas e o acesso ao conhecimento aos seus filhos, o que possibilitaria a ascensão a um bom futuro, principalmente relacionado a um bom emprego. "Pra mudar a vida, né!? Ter uma profissão melhor. Eu tento explicar pra eles assim [. . .] o que eu não consegui eu quero que eles consigam.” (Maria)

[. . .] pra educação dela, pro futuro dela. Eu interrompi meus estudos no segundo colegial por motivos torto, assim que fala né? Não tinha motivo pra eu sai da escola, mas eu sai. E hoje eu quero que ela estude, eu sei que ela é muito inteligente, precisa estuda. Eu sempre to colocando na cabeça dela que é muito importante pro futuro dela, pra ela te um estudo. A vida de todo mundo precisa [ . . . o fundamental que eu acho é a educação. [ . . .] no estudo, na educação, ela se forma. Cresce, vai se forma, te uma profissão. Vai se independente, não vai fica dependendo de marido, de ninguém. Vai te o dinheiro dela. Toda mulher deveria se independente e não precisa de marido né? De namorado e nem de ninguém. Te uma vida profissional, no caso eu acho que a escola é o principal. (Silvia)

Além disso, a importância do tempo de permanência na escola surge principalmente para que a criança não permaneça na rua ou mesmo em casa, envolvida em atividades perigosas e menos importantes do que aquelas oferecidas na escola.

[. . .] têm muitas mães que trabalha e se tivesse estudando meio período e indo embora, a criança iria ficar na rua, não iam ficar fazendo nada, então aqui na escola, eles estudam meio período e brincam o resto da tarde. Então eu acho que é atividade que eles estão fazendo, não ta na rua...porque tem bastante criança perto da minha casa que não estuda, daí eu fico olhando pra rua, estão na rua..soltando pipa, perigo né? Dentro da escola, está seguro. (Cristina)

Os dados sugerem que, diante do discurso das entrevistadas, uma escola que atenda em tempo integral é essencialmente valorizada enquanto um espaço seguro para as crianças do que propriamente pela proposta de ensino e ampliação curricular dos alunos, uma vez que alegam o desconhecimento destas. "[. . .] porque eu não conheço o trabalho da escola."(Lucia)

Essa visão corrobora a ideia de que a escola é considerada um local seguro para a permanência dos filhos, uma vez que oferece atividades importantes para o seu futuro em detrimento da rua e da casa, (Freitas, 2009) e ressalta a confiança depositada na escola pela família no cuidado dos filhos, principalmente na primeira infância (Birman, 2007). 
Além disso, ainda permanece o caráter atribuído à escola de retirada das crianças do mundo da rua para proporcionar-lhes melhores condições, como alimentação, segurança e ocupação do tempo com atividades pré-planejadas (Freitas, 2009).

\subsection{A função da escola para o desenvolvimento das crianças, de acordo com as mães}

A compreensão da relevância da escola para o contexto familiar atual fica mais evidente quando se questiona a respeito do papel e função desempenhados por ambas as instituições para o desenvolvimento da criança.

$\mathrm{Na}$ concepção das entrevistadas, a função desempenhada pela escola é abrangente e transita por meio de diversas atribuições e em alguns aspectos vão ao encontro da proposta de tempo integral de enriquecer o currículo dos alunos com conteúdos formais e informações da educação. Porém, no momento em que as mães atribuem à escola tais funções, isto pode significar o aumento da confiança depositada na escola e o atravessamento do público sobre o privado (Giddens, 2002).

Além das funções constituídas historicamente para a escola, como o desenvolvimento de habilidades cognitivas e o conhecimento, as mães atribuem à escola funções que poderiam ser compreendidas como específicas da família, tais como oferecer carinho, paciência, amor e limites para os filhos, como meios de facilitar o desenvolvimento da aprendizagem. "[. . .] desse bastante atenção, amor pra ele. Paciência pra ele, pra ele pudesse consegui a entende ali as matéria e a desenvolve na escola." (Lucia)

[. . . ] ah, ela é importante, o aprendizado mesmo. Aprende a ter limites porque muitas vezes os pais não colocam limites em casa. Então vindo pra escola, eles sabem o que pode e o que não pode faze, o que é certo e o que é errado. As vezes os pais não tem tempo também pra ensina. Ela ta ensinando e as vezes não tem paciência pra ensina as matérias. Na escola eles vão ensina tudo isso [. . .] mas a escola vai ser assim, aquele preenchimento que ela não tem em casa, entendeu? (Silvia)

Cabe ressaltar que, de acordo com Oliveira e Marinho-Araújo (2010), os progenitores são primordiais para orientar o desenvolvimento e aquisição de comportamentos considerados adequados, considerando assim, padrôes sociais vigentes em uma cultura.

Foi possível notar na fala das mães que a escola deveria suprir aquilo que consideram incapazes de oferecer aos seus filhos, devido à falta de tempo ou então, à falta de conhecimento. 
Porque a educação já vem lá da família e tem que completa na escola com o ensino, pro futuro, porque essas coisa que a escola ensina, os estudo, tudo, o pai e a mãe já não sabe. A não ser que o pai e mãe sejam bem estudado, porque igual assim, a gente, dona de casa não tem como, você não tem a instrução toda pra levar pra dentro de casa, mas você sabe que na escola tem. (Maria)

Bom, eu não consigo ensinar a ler no sistema de agora. Desde que a aula começou eu disse: "não consigo", porque eu aprendi de um jeito, eles começam com letra de forma. [. . .] então não adianta. Porque você vai ensinar eles e eles não entende. Eu não entendo eles e eles não me entende. (Lucia)

Além disso, nos discursos das mães entrevistadas, verifica-se a desqualificação do saber da família em detrimento ao conhecimento científico atribuído à escola, que passa a ocupar um lugar imprescindível na vida dessas famílias. Esse dado aponta novamente para a excessiva confiança depositada pelas mães nessa instituição, inclusive com relação às funções afetivas. Devido a isso, as mães consideram de grande importância a permanência do filho numa escola em tempo integral, em detrimento ao tempo parcial.

Desse modo, as mães atribuem diversas funções à escola, e demonstram também a sensação de que não são tão capazes quanto a escola para promover a educação de seus filhos. Tal fato pode associar-se ao baixo nível educacional que possuem (que varia entre o ensino fundamental e médio incompletos) e à valorização do conhecimento e do saber especialista, em detrimento do saber familiar, necessário para que se possa educar um filho atualmente (Mariotto \& Schaedler, 2013).

\subsection{A importância e o papel da família para o desenvolvimento das crianças}

Quando indagadas a respeito do papel exercido pela família, a concepção das mães entrevistadas revela que tal função restringe-se à afetiva, ou seja, oferecer carinho, apoio, participar das reuniōes escolares e dialogar com os filhos, principalmente com a finalidade de torna-los motivados e felizes. "Eu acho que base familiar, é pai, mãe é tudo, com diálogo, carinho. [. . . E também participar da escola é importante pra animar a criança senão a criança perde o incentivo também" ( Fatima). "A importância para a família é o carinho, a atenção, a base [...]sempre acompanhar o filho na escola né? Ir na reunião, deixa a criança feliz. Quando vai ter reunião, sempre meu filho me lembrando direto: 'mãe, reunião amanhã', porque eu acho que ele tem vergonha deu não ir.” (Cristina) 
Tal fato aponta um paradoxo, pois a função afetiva é atribuída tanto à escola como à família e aponta para o enfraquecimento do lugar parental verificado por Rojas (2010), que demonstra a simetria ou mesmo a inversão na relação estabelecida entre os pais e seus filhos, o que dificulta o desempenho da tarefa de sustentação e apoio necessários para que os filhos possam sentir-se amparados em seu desenvolvimento psíquico. É importante ressaltar que nenhuma das entrevistadas apontou a função de interdição pulsional como responsabilidade familiar. Ao contrário, o aspecto do limite foi igualmente atribuído à instituição escolar. Essa questão pode se relacionar com o desamparo e sentimento de desproteção dos filhos com relação às figuras parentais. Dessa forma, uma hipótese é a de que a escola estaria ocupando inclusive o lugar de autoridade para as crianças (Janin, 2011).

Além disso, o discurso apresentado nos leva a refletir o quanto a valorização do saber técnico-científico divulgado para a educação de crianças não tem colaborado para o esvaziamento verificado nas funçóes exercidas pela família. Tal dado corrobora aqueles apresentados por Biasoli-Alves (2002); Gomes e Zanetti (2011), no que diz respeito às transformações verificadas a respeito das práticas de cuidado e educação dos filhos, no final do século XX. As atitudes e as crenças a respeito da educação dos filhos estão cada vez mais dependentes do conhecimento dos especialistas, tais como os pediatras, os professores e os psicólogos. Pode-se verificar que através de todo o discurso das mães, a centralização do desenvolvimento de seus filhos perpassa a importância da escola e a concepção de que os pais não são tão capazes quanto a escola no que diz respeito às necessidades dos filhos. Uma das justificativas para tal situação é de que as mães não possuem o conhecimento necessário para educar seus filhos, ao contrário da escola, que também seria a sede do conhecimento necessário para o exercício de tal função.

As crianças passaram a receber muitas cobranças do mundo social para que desenvolvam um bom comportamento e correspondam às expectativas sociais, ou seja, um futuro promissor. Dessa forma, a educação dos filhos transformouse: exigir poucas regras é marcado como ideal, e o fundamento da educação é oferecer independência, permitir a iniciativa do filho, fato que poderia nos ajudar a compreender a concepção das entrevistadas de que caberia à família oferecer afeto, carinho, apoio, sobretudo com o objetivo de motivar seus filhos para atingir tal futuro promissor (Biasoli-Alves, 2002; Birman, 2007).

Com relação à posição da família frente ao desenvolvimento da criança, foi perceptível que, apesar da maioria das mães possuírem um trabalho informal, estas relatam falta de tempo para seus filhos, deixando a escola encarregada de exercer algumas funções que poderiam ser atribuídas às próprias mães. Tal 
posicionamento demonstra que manter o filho numa escola que atenda em regime integral pode atender à demanda apresentadas pelas mães.

É possível perceber nos discursos que a posição desempenhada pela família frente ao desenvolvimento das crianças, segundo as mães, sempre está ligada à escola, ou seja, incentivar os filhos no estudo, dialogar com as crianças para que estas prestem atenção nos conteúdos ensinados pela escola e ir à mesma para que esta eduque efetivamente seus filhos. "[. . .] porque a família é tudo. Sem família não tem como desenvolver. [. . .] ah, eu acho que a família tem que incentiva a criança a estuda. Acho que é isso." (Carmem)

\begin{abstract}
Dando mais calma pra ele, mais tranquilidade, passando pra ele não os meus problema, não as minhas inseguranças, não os meus medo, mas passando pra ele motivação: 'Bruno, vamo estuda, tudo é sacrifício, se você não se sacrifica você não vai consegui aprende. Você tem que tê atenção porque se não você não vai consegui se desenvolve, filho. Tem hora pra brinca, tem tempo pra todas as coisas. Na hora que você for estudá, é a hora que você tem que estudá, depois vai te o tempo de você ir no recreio, conversa com seus amigo. Então presta atenção na aula, no que a professora ta ali pra te ensiná. Assim, eu motivo ele, eu falo com ele, eu converso com ele, que ele tem que i na escola, quando ele fala que não quer ir hoje, eu falo que ele tem que ir, porque é 5 dias na semana só, tem o final de semana pra brinca e descansa. (Lucia)
\end{abstract}

No lugar da função de contenção, surge a necessidade de motivar os filhos para os estudos, o que demonstra a mudança no lugar ocupado pelos pais, que passam a ocupar um lugar secundário ao da escola, uma vez que sua principal ação relaciona-se à preocupação com o desempenho e o desenvolvimento futuro dos filhos.

Vale destacar que tal dado reafirma a importância da escolaridade e do conhecimento no mundo atual, ou seja, um bom futuro se relaciona aos estudos e ao saber especializado. Assim, pode-se supor que um dos motivos pelos quais a força da escola seria preponderante ao da família está relacionado ao poder atribuído ao conhecimento no mundo atual. Por isso, nessa pesquisa, fica evidente o valor atribuído a essa instituição de ensino, principalmente quando está atrelada à ampliação da jornada escolar.

Assim, os pais desempenham apenas o papel de mediador entre a criança e o mundo, pois estes "oferecem instrumentos para a apropriação do conhecimento" (Orsi, 2003) e com isso, a função em colocar limites e desempenhar a função afetiva e de autoridade, além de ensinar habilidades psicofísicas até atingir a maturidade adulta, deveriam ser desempenhados pela escola. 


\section{CONSIDERAÇŌESS FINAIS}

Por meio dos discursos apresentados nas entrevistas realizadas pode-se notar um descompasso entre a função familiar e a escolar. Verifica-se que a família deposita grande parte da expectativa e da responsabilidade sobre o desenvolvimento, tanto cognitivo quanto emocional de seus filhos, na instituição escolar, alegando falta de conhecimento e tempo para o desempenho de tais funções. Assim, concebem que seus filhos deverão permanecer mais tempo na escola, local onde poderão ter acesso a atividades úteis para seu futuro, apesar das mesmas mães alegarem possuir poucas informações a respeito das atividades desenvolvidas na escola, principalmente nesse novo modelo de escola com o regime integral. Dessa forma, restaria à escola, por sua vez, incorporar e se responsabilizar por papeis que anteriormente não era necessário desenvolver nesse âmbito institucional.

Os dados apresentados nessa pesquisa apontam que o aspecto mais relevante para as mães entrevistadas é o fato de as crianças possuírem algum lugar seguro e confiável para ficar. Para as mães, existe pouca diferenciação entre a proposta ampliação da jornada escolar e o papel da escola. Tal fato é evidenciado através da análise das falas das entrevistadas, na qual as mesmas só se referem especificamente ao tempo integral em poucos momentos da entrevista, quando citam a importância do tempo de permanência dos filhos na escola como um local seguro e quando alegam desconhecimento sobre a proposta e atividades implementadas na escola para atender a ampliação do tempo de permanência na escola.

Por outro lado, prevalece a visão de que a rua, o brincar e mesmo as atividades desenvolvidas na própria casa têm uma importância menor, se comparadas àquelas oferecidas na escola. Ou seja, a importância do estudo e do acesso ao conhecimento surge em detrimento do brincar livre e aparentemente descompromissado com o aprendizado formal.

Os achados sugerem que as mães valorizam o aprendizado cognitivo de seus filhos e tal aprendizado localiza-se na escola. Ao mesmo tempo, referem sua incapacidade em oferecer os conhecimentos necessários para o desenvolvimento de seus filhos. Tais dados refletem o enfraquecimento da família em detrimento do fortalecimento das instituições e do saber científico para o desenvolvimento das crianças na atualidade (Gomes \& Zanetti, 2011). Assim, segundo Birman (2007), existiria um processo no qual se exige das escolas funçôes que anteriormente eram da família e a instituição escolar reluta em cumprir esses novos papeis destinados a ela, pois tal fato modificaria inteiramente sua estrutura e concepção. Assim, as creches e as escolas de ensino fundamental estariam cumprindo, em parte, o desenvolvimento de socialização primária das crianças, papel anteriormente de exclusividade da família. 
É possível compreender que as concepções apresentadas pelas mães entrevistadas representam as dificuldades vivenciadas pelas famílias em oferecer a educação e o apoio necessários ao desenvolvimento de seus filhos, em decorrência de todo o cenário de transformaçóes e mudanças apresentado anteriormente. As famílias depositam confiança e a responsabilidade pela educação de seus filhos no conhecimento especializado, nesse caso, na escola e apontam para dúvidas e questionamentos sobre a própria capacidade para educar sua prole, alegando falta de conhecimento, o que reflete que, na concepção das mães, é necessário conhecimento científico e especializado para realizar a tarefa de educação dos filhos (Janin, 2011).

Os resultados obtidos nessa pesquisa apontam que o fortalecimento da escola é o aspecto mais relevante para as mães entrevistadas. E é importante salientar que nos discursos analisados, a relevância recai sobre o papel da escola, sendo que a ampliação do tempo de permanência e seus objetivos são desconhecidos e pouco diferenciados. Ou seja, são incorporados como mais um dos papéis desempenhados pela instituição escolar em detrimento de um concomitante estreitamento nas funções desempenhadas pela família.

Desse modo, permanece a necessidade da psicologia e da própria escola repensarem seu posicionamento e o tipo de trabalho a ser desenvolvido, seja com as crianças e/ou suas famílias, diante dos dados verificados na presente pesquisa. Seria importante a reflexão a respeito das formas de relação estabelecidas entre as instituições para o cumprimento das devidas funções no desenvolvimento das crianças, ressaltando a necessidade em repensar as funções que deveriam ser desempenhadas por cada uma, no sentido do fortalecimento e da colaboração mútua entre tais instâncias e não o fortalecimento de uma em detrimento da outra, como é perceptível neste trabalho.

Além disso, cabe apontar a importância do desenvolvimento de outras pesquisas que possam contribuir para a compreensão de tal situação, uma vez que, apesar de todas as transformações ocorridas, ainda não foi possível encontrar novas formas de relações entre a família e escola que colaborem para o fortalecimento e o enriquecimento de todos os atores/sujeitos envolvidos nesse processo. Sobretudo, compreender as necessidades de pais, crianças e escola é imprescindível para que se possa oferecer um ambiente que colabore, de fato, com o desenvolvimento integral das crianças envolvidas nesse processo. Os dados da presente pesquisa demonstram o fortalecimento das instituições apontado por Giddens (1991) que descreve sobre a aproximação às características de confiabilidade relacionadas, ou até mesmo confundidas, com amizade e intimidade e a relação de dependência verificada na família, que parece fragilizar cada vez mais seu papel e função. 


\section{REFERÊNCIAS}

Ackerman, N. (1986). Diagnóstico e tratamento das relaçôes familiares. Porto Alegre: Artes Médicas.

Ariès, P. (1981). História social da criança e da família. Rio de Janeiro: LCT.

Biasoli-Alves, Z. M. M. (2002). A questão da disciplina na prática de educação da criança, no Brasil, ao longo do século XX. Rev Veritati. (2),243-259.

Birman, J. (2007, junho). Laços e desenlaces na contemporaneidade. Jornal de Psicanálise, São Paulo, 40(42), 47-62.

Campos, R. O., Furtado, J. P., Passos, E., \& Benevides, R. (2008). Pesquisa avaliativa em saúde mental: desenho participativo e efeitos da narratividade. São Paulo: Aderaldo \& Rothschild.

Castro, A. \& Lopes, E. R. (2011, abril/junho) A Escola de Tempo Integral: desafios e possibilidades. Ensaio: aval. Pol. Educ., Rio de Janeiro, 19 (71), 259-282,

Cury, C.R.J. (2002, julho). Direito à Educação: Direito à Igualdade, Direito à Diferença. Cadernos de Pesquisa, (116), 245-262

Denzin, N. K. \& Lincoln, Y. S. (eds.) (2005). The SAGE handbook of qualitative research. California: SAGE Publications.

Dolto, F. (1999). As etapas decisivas da infância. M. E. Galvão (Trad.), São Paulo: Martins Fontes.

Freitas, M. C. (2009). A criança-problema: formas de coesão contra o pobre e formas partilhadas de preterição social. In: A. Mota \& L. B. Schraiber (Eds), Infância \& saúde: perspectivas históricas. (pp. 60-88). São Paulo: Hucitec/ Fapesp.

Giddens, A. (1991). As consequências da modernidade. R. Fiker (Trad.). São Paulo: Ed UNESP.

Giddens, A. (2002). A modernidade e identidade. P Dentzien (Trad.). Rio de Janeiro: Ed Jorge Zahar.

Gomes, I. C. \& Zanetti, S. A. S. (2011). A "fragilização das funções parentais" na família contemporânea: determinantes e consequências. Temas em Psicologia. $19(2), 491-502$. 
São Paulo. Secretaria de Estado da Educação. Coordenadoria de Estudos e Normas Pedagógicas. (2011). Educação integral: escola de tempo integrallaluno de tempo integral. São Paulo.

Janin, B. (2011). El sufrimento psíquico en lós niños: psicopatologia infantil y constituición subjetiva. (p. 264). Buenos Aires: Centro de Publicaciones Educativas Y Material Didáctico.

Mariotto, R.M.M. \&Schaedler, M.C. (2013). Ainsustentável psicomedicalização da criança e seus impactos no discurso familiar. In: I. K. Marin, \& M. O. Aragao, (Orgs.) Do que fala o corpo do bebê. São Paulo: Escuta, p. 77 - 89.

Oliveira, C. B. E. \& Marinho-Araújo, C. M. (2010). A relação família-escola: intersecçóes e desafios. Estudos de Psicologia. Campinas, 27(1), 99-108.

Orsi, M. J. S. (2003, novembro). Família: reflexos da contemporaneidade na aprendizagem escolar. In: Anais, 1 Encontro Paranaense de Psicopedagogia, Paraná: ABPpPR,

Peräkylä, A. (2005). Analyzing text and talk. In: N. K. Denzin \& Y. S. Lincoln (Eds.). The SAGE handbook of qualitative research. (pp.869-881). Califórnia: SAGE Publications.

Pucci, L. F. S. (2005). A proposta da escola de tempo integral no Estado de São Paulo: novos desafios para a escola pública e para a formação de professores. Cadernos de Pós-Graduação, Educação, São Paulo, 4, 75-83.

Rocha, A. P. (2005). Palco de Conflitos: escola pública no capitalismo, aparelho hegemônico ou instrumento de contra-hegemonia? (Dissertação de Mestrado). Universidade Estadual de Maringá. Maringá.

Rojas, M. C. (2010). Desamparo y desmentida en la família actual: intervenciones del analista. Vínculo 7, (2), 2-7. Recuperado a partir de http://pepsic.bvsalud. org/pdf/vinculo/v7n2/n2a03.pdf

Roudinesco, E. (2003). A familia em desordem. Rio de Janeiro: Zahar.

Szymansky, H. (2004, maio/agosto). Práticas educativas familiares: a família como foco de atenção psicoeducacional. Revista Estudos de Psicologia, PUCCampinas, 21 (2),5-16

Vetorazzi, N. G. (2011). Escola de tempo integral: da convenção à participação. (Dissertação de Mestrado). Universidade Cidade de São Paulo, São Paulo. 